IdeAs

Idées d'Amériques

$7 \mid 2016$

Cinéma et histoire dans les Amériques

\title{
L'arrière-pays algonquien pendant la Révolution américaine
}

Anne-Marie Libério

\section{OpenEdition}

1 Journals

\section{Electronic version}

URL: https://journals.openedition.org/ideas/1626

DOI: 10.4000/ideas.1626

ISSN: 1950-5701

\section{Publisher}

Institut des Amériques

\section{Electronic reference}

Anne-Marie Libério, "L'arrière-pays algonquien pendant la Révolution américaine", IdeAs [Online], 7 |

2016, Online since 20 July 2016, connection on 19 October 2022. URL: http://

journals.openedition.org/ideas/1626; DOI: https://doi.org/10.4000/ideas.1626

This text was automatically generated on 19 October 2022

\section{(c) (i) (9)}

Creative Commons - Attribution-NonCommercial-NoDerivatives 4.0 International - CC BY-NC-ND 4.0 https://creativecommons.org/licenses/by-nc-nd/4.0/ 


\title{
L'arrière-pays algonquien pendant la Révolution américaine
}

\author{
Anne-Marie Libério
}

\section{Introduction}

1 Malgré les bouleversements subis par les nations amérindiennes pendant l'époque coloniale, les gouvernements tribaux décidèrent majoritairement, le plus souvent indépendamment les uns des autres, mais également par le biais de coalitions, de s'allier aux Britanniques pendant la Révolution américaine. Au même titre que les colons, ces Amérindiens furent désignés comme «loyalistes» ou "Tories». Le parti adverse, favorable à l'indépendance des treize colonies, était composé des insurgés (« insurgents ») ou « patriotes ».

2 Si l'alternative loyaliste peut à première vue sembler paradoxale pour les Amérindiens, elle s'explique en partie par les garanties que la Couronne britannique leur offrit, à l'issue de la guerre de Sept Ans, et suite au soulèvement de plusieurs nations indiennes, appelé rébellion de Pontiac'. Par la Proclamation royale d'octobre 1763, la métropole détermina que les Appalaches serviraient de frontière entre Amérindiens et Européens, afin de limiter l'empiètement des colons sur le pays indien. En outre, la métropole rendit obligatoire le recours à une licence, octroyée par les officiers de la Couronne à quiconque tentait obtenir des parcelles au-delà de la frontière. Cette mesure servait à empêcher la spéculation foncière, conduisant fréquemment à la spoliation des autochtones.

3 Même si les Britanniques n'eurent pas les moyens militaires suffisants pour faire appliquer la Proclamation royale, en comparaison, aux yeux des Amérindiens loyalistes, les insurgés apparaissaient bien moins enclins à freiner l'installation des Américains convoitant les territoires qui leur appartenaient. Si la protection des terres fut au centre des préoccupations des autochtones, l'assurance que leur souveraineté serait respectée à l'issue de la guerre motiva aussi leur décision, lorsqu'ils durent choisir entre les deux camps, ou se tenir à l'écart du conflit. 
Du point de vue de la jeune nation, sortie victorieuse mais fortement endettée de la guerre, les terres de l'Ouest représentaient l'une de ses richesses principales. Benjamin Franklin et George Washington eux-mêmes s'intéressaient à la spéculation foncière à l'ouest des Appalaches ${ }^{2}$. Sans attendre l'issue du conflit, les États-Unis tentèrent de s'approprier des terres indiennes, par le biais de la diplomatie. Dès les premières années de son existence, la jeune république tenta en effet de véhiculer l'image d'une nation disposée à négocier avec les autochtones sur un pied d'égalité, comme elle le faisait avec les nations étrangères. Les Amérindiens, dont le rapprochement avec les Britanniques parvint par endroits à ébranler la confiance des insurgés pendant les campagnes militaires, ne devaient pas envisager la nouvelle nation comme une menace pour leurs droits souverains.

5 Sous le couvert de la « légalité » et de la "philanthropie », comme le soulignait Alexis de Tocqueville (Tocqueville, 1835, p. 346-347), le gouvernement fédéral conserva le système des traités, initié au XVIIe siècle. Les États-Unis perpétuèrent également le déroulement des sessions précédant la signature des traités, instauré par les représentants de la Couronne et des assemblées coloniales. Les négociations conclues pendant la Révolution reposèrent ainsi sur les échanges entre les représentants du Congrès Continental, la délégation amérindienne (dont la légitimité représentative fut souvent exagérée par les Américains), et les commandants des forts militaires à proximité desquels les discussions avaient lieu³. Historiens et anthropologues s'accordent sur le fait que les traités indiens furent « importants parce qu'ils marquent les premiers efforts de la jeune nation à exercer son indépendance en termes de diplomatie $»^{4}$.

Cependant, comme en témoigne la Déclaration d'Indépendance, la méfiance et l'inimitié furent très tôt exprimées par les dirigeants américains. Outre l'accusation portée globalement contre les autochtones de s'allier au roi George III, les Pères Fondateurs les décrivirent comme des "sauvages sans pitié, dont la manière bien connue de faire la guerre est de tout massacrer sans distinction d'âge, de sexe ni de condition ${ }^{5} »$.

7 Nous analyserons ci-après le rôle de différents acteurs, Euro-Américains et Amérindiens, appartenant aux sphères religieuse, diplomatique et militaire, dont le dessein fut de persuader les nations dans leur ensemble, ou parfois simplement quelques individus, d'adopter la cause loyaliste, celle des insurgés, ou enfin, de renoncer à s'engager militairement dans le conflit. Nous nous intéresserons en particulier aux interactions avec les Delawares de l'arrière-pays (ou «backcountry»), dans la région de l'Ohio (ou « Ohio Country»).

\section{Alliances et souveraineté}

8 Alliés aux Français pendant la guerre de Sept Ans, les Delawares et les Shawnees (deux nations de la famille linguistique algonquienne) perdirent une partie importante des terres accordées dans les années 1730 par les Iroquois, dont ils recevaient la protection en échange de leur soumission aux Six Nations ${ }^{6}$. En cédant les terrains de chasse des Shawnees lors du traité de Fort Stanwix de 1768, les Iroquois obligèrent les trois clans delawares et les Shawnees à se déplacer et à recomposer de nouveaux villages ${ }^{7}$. 
9 En raison de cet affaiblissement, et par l'influence des pasteurs moraves pacifistes dirigés par David Zeisberger et John Heckewelder, arrivés en 1772 dans l'Ohio Country, les représentants des clans delawares s'entendirent pour rester à l'écart de la guerre jusqu'en 1778. Toutefois, les Delawares ne percevaient pas non plus les insurgés comme des alliés présentant un réel avantage. Dans leurs échanges commerciaux et diplomatiques, les Delawares interprétèrent la pauvreté des présents et des marchandises que les Américains leur fournissaient comme du mépris, de la négligence ou un signe de dénuement qui décrédibilisaient les patriotes ${ }^{8}$. Ces derniers ignoraient de fait la portée diplomatique des présents, qu'ils assimilaient à une forme de corruption des représentants amérindiens. Thomas Jefferson conserva cette idée, et déclara par exemple en 1802 que les États-Unis devaient faire appel à «la bonne volonté [...] des chefs au moyen de largesses "

10 L'alliance avec les insurgés fut finalement l'œuvre du chef delaware Quequedegatha, appelé White Eyes ou George White Eyes par les moraves et les Britanniques. Par l'argument que les Delawares étaient sur le point d'être attaqués par des nations autochtones hostiles, il persuada son peuple qu'une alliance avec les Américains pouvait renforcer leurs défenses. Les représentants des deux autres clans, Captain Pipe (ou «Hopocan») et Captain John Killbuck, l'accompagnèrent aux négociations de Fort Pitt, qui aboutirent au traité du 17 septembre $1778^{10}$. Les États-Unis et les Delawares s'engageaient en premier lieu à se "pardonner mutuellement » et pour toujours, les attaques qu'ils s'infligèrent dans le passé (article 1). Outre la promesse d'assurer aux Delawares et à leurs descendants leurs droits territoriaux (article 6), les Américains impliquaient les Amérindiens à leurs côtés face à la Grande-Bretagne (article 3). Comme preuve de leur bonne volonté envers leurs alliés, les États-Unis promettaient de construire un fort "à leurs frais ", où des soldats américains défendraient les femmes et les enfants delawares, pendant que les "meilleurs guerriers» de la nation combattaient les Britanniques :

les États-Unis sont engagés dans une guerre juste et nécessaire, pour défendre [...] leur liberté et leur indépendance, contre le roi d'Angleterre [...] et comme le roi possède encore plusieurs forts [...], dont la reprise est d'une grande importance pour la paix et la sécurité des parties contractantes, et comme la meilleure route pour les troupes des États-Unis vers certains de ces forts consiste à traverser les terres de la nation delaware, les dits représentants [...], acceptent par le présent document d'accorder la libre circulation à travers leur nation aux dites troupes, et de [leur] procurer des provisions de maïs, viande, chevaux [... $]^{11}$.

\section{Jeux d'échelles (locale et intertribale)}

11 Cette entente, conclue dans la sphère diplomatique, reflétait mal les réalités des échanges entre Amérindiens et Américains. Lorsque l'on retrouva White Eyes sans vie au début du mois de novembre 1778 près de Pittsburgh ${ }^{12}$, et même si la cause de sa mort (variole ou assassinat) ne fut pas clairement établie ${ }^{13}$, les Delawares réagirent comme si le décès du chef était à imputer aux Américains de l'arrière-pays, dont les autorités fédérales ne parvenaient pas à contrôler les actions, et qui ne se sentaient pas concernés par les traités signés avec les autochtones. L'historien Richard White décrivit les motivations des habitants euro-américains de la frontière, comme étant fort éloignées de celles des dirigeants britanniques et américains ${ }^{14}$ : 
les patriotes [...] de l'arrière-pays perdirent des parents et des biens par la faute des Indiens, et la plupart d'entre eux se mirent à les haïr. Ils tuaient des Indiens (autant amis qu'ennemis, là où ils en trouvaient) sans réellement penser aux conséquences de leurs gestes pour la cause révolutionnaire. Quant aux Tories de l'arrière-pays, leur loyauté envers le roi comptait souvent moins que le désir de se venger de dommages privés sur leurs voisins révolutionnaires.

Comme les Euro-Américains, les Amérindiens ajustèrent leurs alliances en fonction de l'évolution des affaires locales, qui les concernaient au plus près, plutôt que d'un sentiment de loyauté envers l'une ou l'autre des factions impliquées dans la guerre d'indépendance. L'une des priorités des guerriers delawares devint alors de venger White Eyes, ce qui impliquait un changement de camp. Ils allaient désormais défendre les Britanniques, non pas parce qu'ils voulaient faire obstacle à l'indépendance et aux aspirations des Américains, mais parce qu'ils imaginaient que les Britanniques nuiraient moins que les insurgés à leur propre souveraineté, et à la légitimité de leurs chefs. En raison de ce retournement, s'ensuivirent plusieurs mois de représailles, jusqu'au massacre de Gnadenhutten (Ohio), où une milice tua " plus de 90 Delawares, dont un tiers de femmes et 34 enfants » de la mission morave, en mars $1782^{15}$. Selon John Heckewelder qui n'était pas présent, mais auquel un jeune rescapé laissé pour mort raconta les faits, les insurgés de l'arrière-pays ne les considéraient " pas comme des chrétiens [...], ils étaient tous déclarés ennemis et guerriers $»^{16}$.

En somme, la guerre qui opposa les Britanniques aux Américains et à leurs alliés vint s'ajouter aux affaires antérieures, conduites par les autochtones entre eux et avec les Européens (pasteurs, marchands, diplomates - allemands, français, espagnols, écossais, anglais), en pays indien. Des peuples aussi puissants que les Six Nations, qui se divisèrent et s'entretuèrent pendant la guerre, ne retrouvèrent jamais l'influence dont ils bénéficiaient avant la Révolution, même s'ils démontrèrent des capacités d'adaptation des deux côtés de la frontière, tels que les Mohawks loyalistes, exilés au Canada $^{17}$.

Dans les interactions avec les Euro-Américains, la Révolution eut aussi des conséquences désastreuses qui compliquaient les questions de la terre et de la souveraineté, en y ajoutant la problématique ethno-raciale. Comme le rappelle Richard White, « tout enfant élevé de la sorte apprend à haïr un Indien, parce qu'il en entend toujours parler comme d'un ennemi $»^{18}$.

Même si le gouvernement fédéral, en particulier sous la présidence de Thomas Jefferson, continua d'appuyer les initiatives de pasteurs visant à "civiliser » les autochtones ${ }^{19}$, leur permettant de se maintenir à l'est des Appalaches, puis à l'est du Mississippi après l'achat de la Louisiane en 1803, pendant la trentaine d'années qui suivirent la Révolution, la peur du "sauvage sans pitié» de la Déclaration d'Indépendance se perpétua à la fois dans l'imaginaire collectif et les actions locales. Le rejet des autochtones, perçus comme ennemis de la République, culmina sous l'administration jacksonienne, par la politique du déplacement forcé des peuples du Sud-Est vers l'État actuel de l'oklahoma, sous contrôle militaire, faisant ainsi échouer sans ambiguïté à la fois diplomatie et terrain(s) d'entente à l'est du Mississippi. 


\section{NOTES}

1. Élise Marienstras, "Les réprouvés de la Révolution: nations indiennes et guerre d'indépendance ", in Élise Marienstras et Bernard Vincent (dir.), Les Oubliés de la Révolution américaine : femmes, Indiens, Noirs, quakers, francs-maçons dans la guerre d'Indépendance, Nancy, Presses universitaires de Nancy, 1990, p. 26-27 ; Richard White, The Middle Ground, Indians, Empires and Republics in the Great Lakes Region, 1650-1815, Cambridge, Cambridge University Press, 1991, p. 269-314

2. Colin G. Calloway, "La révolution américaine en territoire indien ", Annales historiques de la Révolution française, $\mathrm{n}^{\circ}$ 363, janvier-mars 2011, p. 133

3. Vine Deloria, Jr. et Raymond J. DeMallie, «Pre-Revolutionary War Treaty Making », Documents of American Indian Diplomacy. Treaties, Agreements, and Conventions, 1775-1979, vol. 1, Norman, OK, University of Oklahoma Press, 1999, p. 12

4. ibid.

5. United States, «In Congress, July 4, 1776. The Unanimous Declaration of the Thirteen United States of America, Baltimore, in Maryland : Printed by Mary Katharine Goddard, 1777 ", in Library of Congress, Continental Congress Broadside Collection, Documents from the Continental Congress and the Constitutional Convention, 1774-1789, https://www.loc.gov/item/90898037/, page consultée le 20 juillet 2016

6. Hermann Wellenreuther, "White Eyes and the Delawares' Vision of an Indian State", Pennsylvania History: A Journal of Mid-Atlantic Studies, vol. 68, n 2, printemps 2001, p. 142

7. Marienstras, op. cit., p. 32

8. White, op. cit., p. 380

9. Andrew A. Lipscomb (dir.), The Writings of Thomas Jefferson, volume 14, Washington, D.C., The Thomas Jefferson Memorial Association, 1903, p. 376

10. Charles J. Kappler, "Treaty with the Delawares, 1778 ", Indian Affairs: Laws and Treaties, volume 2, Washington : Government Printing Office, 1904, p. 3

11. ibid.

12. Entrée du journal de David Zeisberger, datée du 20 novembre 1778, « we received news in a letter from Colonel Gibson that [...] Colonel White Eye had died not far from Pittsburgh 15 days ago ", Zeisberger, 2005, p. 481

13. White, op. cit., p. 385-386 ; Earl P. Olmstead, David Zeisberger: A Life among the Indians, Kent, Ohio, The Kent State University Press, 1997, p. 285

14. White, op. cit., p. 378

15. John Heckwelder, A Narrative of the Mission of the United Brethren among the Delaware and Mohegan Indians, Philadelphia, Published by McCarty \& Davis, 1820, p. 321

16. ibid., p. 317

17. Alan Taylor, Divided Ground: Indians, Settlers, and the Northern Borderland of the American Revolution, New York, Knopf, 2006

18. White, op. cit., p. 366

19. William G. McLoughlin, The Cherokees and Christianity, 1794-1870, Essays on Acculturation and Cultural Persistence, Athens, Georgia, University of Georgia Press, 1994 


\section{AUTHOR}

\section{ANNE-MARIE LIBÉRIO}

Anne-Marie Libério est doctorante en études nord-américaines sous la direction de M. Bertrand Van Ruymbeke à l'Université Paris 8. Elle travaille sur les interactions entre les pasteurs anglicans de la Society for the Propagation of the Gospel et les esclaves, les Amérindiens et les colons dissidents des colonies de Caroline du Sud et de New York au XVIIIe siècle. 